\title{
Influence of culture on non-English majors English listening and oral training acquisition
}

\author{
Peng Sui \\ Zhengzhou university of industrial technology.Henan.China
}

\begin{abstract}
In this paper, comparing the culture of mother tongue and target language, we try to explore the positive transfer of native culture in non-English majors English speaking acquisition and make certain the accurate comprehension and expression in the cross culture communication. Language knowledge and social culture are the two main factors that influence the acquisition of non-English majors English. During the whole process of non-English majors English acquisition, we should pay more attention to the social cultural knowledge, and lay emphasis on the dynamic integration of language knowledge and cultural knowledge.
\end{abstract}

\section{Introduction}

Language knowledge and social culture are the two main factors that influence the acquisition of non-English majors English. The former refers to the vocabulary and grammar, which is the most influential one. Meanwhile, the latter also has great effects on the competence that cannot be neglected. Among the learners of similar non-English majors English knowledge, the ones who know more social culture, have the better competence[1].In the meantime, we should lay more emphasis on inheriting our native culture through the means of non-English majors English. It is inadvisable to learn non-English majors English by giving up the profound Chinese culture and national characteristics. In the Chinese cultural background, the cross cultural communication should be carried out in the light of respecting principle, on an equal footing of mutual absorption and integration, and ultimately achieved the joint development.

In most cases, the Chinese students find troubles in non-English majors English communication. The reasons come from the problems in Chinese foreign language education: which was carried out without the consideration of mother langue and native culture, over emphasized the negative transfer of native langue in foreign language education, casted off the influence of mother tongue by mistake to learn foreign language. At present, the majority of non-English majors English learners got insufficient consciousness of culture importance, simply regarded non-English majors English learning was composed of vocabulary and grammar, by the means of imitation and recitation. There lies the great gap between their language skill and the cultural ability. Therefore, during the whole process of non-English majors English acquisition, we should pay more attention to the social cultural knowledge, and lay emphasis on the dynamic integration of language knowledge and cultural knowledge. Meanwhile, comparing the culture of mother tongue and target language, we try to explore the positive transfer of native culture in non-English majors English acquisition and make certain the accurate comprehension and expression in the cross culture communication[2].

Under the Chinese cultural background, the contents of non-English majors English acquisition of our Chinese students consist of two levels: the surface and the deep. The surface level refers to the cultural connotation of vocabulary, language style and manners and customs of two languages. The deep level refers to the thinking manner, nation psychology and values, with a principal eye to the cultivation of cultural insight, comprehension and creation.

To explore the similarity of non-English majors English and Chinese culture

The culture overlapping comes from the human being's similar thinking towards the society and nature, which lay the foundation of cross cultural communication. There is an old saying in non-English majors English: every potter praises his own pot. In Chinese, we have the equal one: Wang po mai gua, zi mai zi kua. Both of the sayings bear the same meaning in two languages. The case concerning the commendatory words and derogatory ones reflects the nation's appraisal view on the behavior and thinking. For instance, in non-English majors English there are approving words: kind, nice and diligent, the corresponding words in Chinese are: shanliangde, meilide, 
qinfende; Derogatory words in non-English majors English are: cruel, ugly and lazy, in Chinese we also have the bad words : cankude, chouloude, landuode.

\section{The Behavioral Learning Model}

The behavioral learning theory emphasizes the learning environment and condition elements, the elements of environment and conditions should be appropriate, adequate and can be tried. Appropriateness refers to the two factors, namely, the condition and the environment should be consistent with some kind of behavior; adequacy refers to the environmental factor and the condition factor should be full, complete and true during the process of learning, which also should be in full accordance with the corresponding conditions that are required during the process of learning. As Skinner's experiments proved that through the leverage as the condition factor, the animal can touch the leverage so as to get the food timely; while try refers that one kind of behavior must overcome the disadvantages caused during the process of environment and conditions. According to foreign language teaching, the teaching activity is a kind of relationship to between teachers and students provide stimulation and accept stimulation.

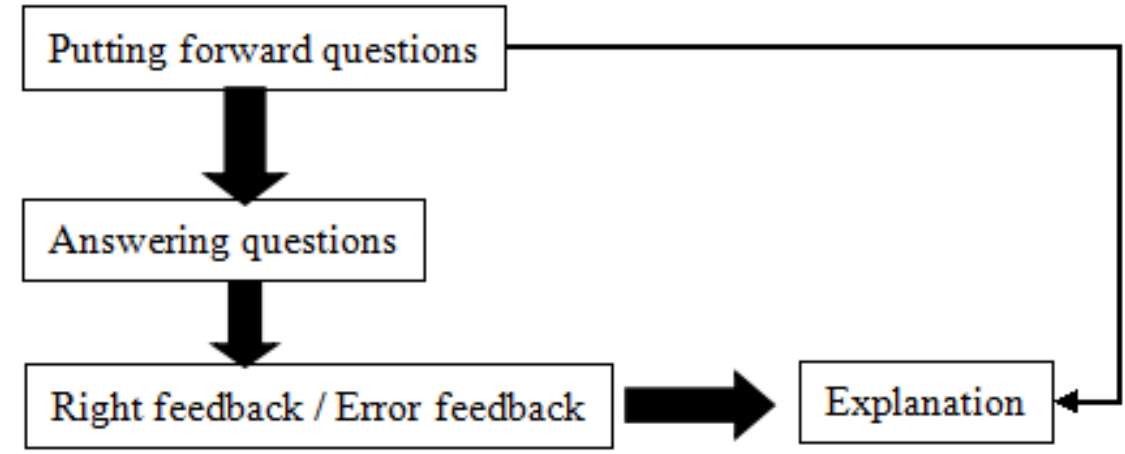

Fig. 1 Teaching graph based on the theory of behavioral learning teaching model

According to Lalandel, "in non-English majors English teaching, cultural learning will ultimately lead to a liberation of the mind, to greater international understanding and cooperation, and toward an appreciation of or at least respect for other people's ways and values"[4]. Under the Chinese culture background, the input of Chinese culture should be implied into the whole process of non-English majors English acquisition, which is instructive and operative.

To eliminate the blind spot of vocabulary learning

Vocabulary is the very closest factor to connect the culture in the linguistic elements. In every language, no dictionary may exhaust the cultural connotation of a word, which is rather abundant. The blind spot of vocabulary cultural implication usually convey the inexact and even wrong meanings, and influence their comprehension and expression. Therefore, in the process of acquisition, vocabulary learning will not rest on its meaning and usage, but its cultural connotation, especially its concrete usage in true cultural context.

The inequivalence of cultural implication

In non-English majors English and Chinese languages, the inequivalence of vocabulary manifested as the value-added or reduced information. In other words, the same word, bears the totally opposite meanings in non-English majors English and Chinese culture.

There is the converse contrast in the love and hate to animals in western and eastern culture. Take “dog” for example, in Chinese, there are so many derogatory words composed of dog: hanjianzougou, langxingoufei, gouzhangrenshi. While on the contrary, it is the common occurrence that the approving words concerning with dog: every dog has his day; love me, love my dog.

The non-equivalence of cultural implication

Every culture has their own specific words to form such kind of cultural vacancy, which is not understood by other nations, and also is liable to be misinterpreted. In non-English majors English and Chinese languages, there are so many words concerning with religion, myth and history, bearing the abundant meanings of national culture. For instance, there are so many words in non-English majors English: priest, pastor, minister, clergy. The corresponding word in Chinese is 
only one "mushi". The cultural connotation and trivial difference must be put in the true context. At the same time, some folk words in Chinese are difficult to match the non-English majors English words, such as huabiao, xiangsheng, wuhaojiating, etc.

To understand the difference of language style in non-English majors English and Chinese

In accordance of Sapir-Whorf hypothesis, language is the guide for users to understand the social reality, which deeply influences their thought and perception. Every language has its own specific pronunciation, vocabulary, grammar and communicative style.

Difference of discourse mode

In non-English majors English, the passive voice is frequently used, while the active voice is the regular application for Chinese speakers. For example, in non-English majors English, we commonly say "the work has been finished and the difficulties overcome". But the sentence will be translated into Chinese as active voice: gongzuowanchengle, kunnankefule. For all the Chinese passive verbs widely existed, such as "bei, rang, gei”, the active voice is still often seen. This phenomenon reflects that the subject and object of an action are deliberately made obscure in Chinese cultural background. The non-English majors English speakers, however, must make clear their identity due to their strong subject consciousness.

Difference of discourse structure

The discourse structures in non-English majors English and Chinese are completely different, the former show liner discourse structure, while the latter present circular/spiral/indirect one. The direct and indirect expressions are determined by various cultural concepts[3]. Influenced by Chinese traditional culture, the speakers lay the focus in the terminal position due to their polite and modest language habits. On the contrary, the westerners put the point in the first place because of their individual and active non-English majors English communication.

non-English majors English is a hypotactic language and Chinese is a paratactic one. That is to say, a large number of logic conjunctions are always applied in non-English majors English, for instance: and, but, then, otherwise, etc. While the Chinese syntactic structure is precisely arranged, their logical structures are usually implied in the deep structure. For example, "wobabashiyisheng, womamashizhufu", the corresponding translation should be "My father is a doctor and my mother is a housewife". In spoken language, the neglect of conjunction "and" is the common Chinglish of the Chinese learners.

To improve the teaching contents

In the present non-English majors English class, the course contents are mainly organized by function and situation, in which the cultural information is integrated into text, or presented by note and supplementary reading. The choice of the cultural function and situation offer the surface input of culture to the language learners, which is insufficient in the range and profundity.

The mother tongue and native culture play the crucial role in foreign language learning. Noticing the cultural phenomenon of native language and target one, the learners should make comparison to find the similarities and differences, try to explore the reasons and form their individual judgment. It is clearly stated that the presentation of non-English majors English and Chinese culture in teaching materials should be equally put in the comparative cross cultural circumstances, instead of being isolated with each other.

To build the cultural equality

The cultural connotation can be enriched by exchange and conflict, which is built on the basis of equality. The learners should understand that it is natural to crash and misunderstand in their cultural communication because of the cultural difference. The timeless exchange may inspire and realize the real communication and mutual understanding, when it is filled with respect, tolerance, equality and freedom. The bilateral cross cultural communication should be built on the mutual understanding of cultural characteristics and respect of cultural habits. Only the sufficient understanding will ensure and create a sort of dynamic peace based on the maintaining of language identity. 


\section{CONCLUSION}

According to Feuerstein R, the first language plays important role in foreign language learning, which is used in every level of acquisition. Foreign language learning stems from the communicative needs, aims to successfully communicate with foreigners to use their elite for ourselves [5]. Persisting in taking multi-cultural perspective as the value orientation, we try to help our learners to comprehend their own native culture and enjoy their proper cultural respect. On the foundation of native source acknowledgement, equal, comprehensive and respectful cultural view will be built by absorbing the best to obtain the necessary concept of value, emotional attitude and knowledge and skills for the coming multi-cultural society. The peaceful coexistence and cultural equality will be realized under the circumstance of social justice.

\section{REFERENCES}

[1]. Altenberg B. 2002.Computer Learner Corpora, Second Language Acquisition and Foreign Language Teaching. Amsterdam \& Philadelphia: Benjamins. Pp:37-54.

[2]. Biber D, Conrad S, Reppen R.1998.Corpus Linguistics: Exploring language structure and use. Cambridge: Cambridge University Press. pp::12-19.

[3]. Lalandel. Doing Culture Cross-cultural Comminication in Action. Beijing: Foreign Language Teaching and Research Press. 1998; 81-120.

[4]. Ellis R.1994.The Study of Second Language Acquisition. London: Oxford University Press.pp: $132-136$

[5]. Feuerstein R, Klein PS, Tannenbaum. Mediated Learning Experience: Theoretical, Psychological and Learning Implications. London: Freueden Press. 2002; 40-43. 